\title{
Soaring seas, forest fires and deadly drought: climate change conspiracies and mental health
}

\author{
Alexander Jack, (1) Reena Panchal (1)
}

BJPsych Bulletin (2021) 45, 210-215, doi:10.1192/bjb.2021.7

University of Wolverhampton, UK

Correspondence to Alexander Jack (a.jack@wlv.ac.uk)

First received 6 Oct 2020, accepted 8 Dec 2020

(c) The Author(s), 2021. Published by Cambridge University Press on behalf of the Royal College of Psychiatrists. This is an Open Access article, distributed under the terms of the Creative Commons Attribution licence (http:// creativecommons.org/licenses/by/4. $0 /$ ), which permits unrestricted re-use, distribution, and reproduction in any medium, provided the original work is properly cited.
Summary There is scientific consensus that anthropogenic climate change is real and that it provides an existential threat to humanity and the planet. In this article, we focus on climate change conspiracy theories and the impact of such beliefs on mental health. We discuss the psychiatric disorders that might be relevant to conspiracy belief endorsement and we present the underlying psychological mechanisms. We note that there is little to no literature to associate beliefs about climate change with serious mental health conditions. However, we anticipate that such beliefs may manifest pathologically in psychiatric presentations as climate change becomes increasingly at the forefront of the global agenda.

Keywords Psychotic disorders; depressive disorders; personality disorders; phenomenology; schizophrenia.
There is a consensus among climate scientists that anthropogenic climate change is real, harmful to the environment and a threat to our futures. ${ }^{1}$ Despite this, climate change denial and scepticism are prominent in social and political discourse, with support from influential public figures. $^{2}$ Conspiracy theories are bedfellows of climate denialism and scepticism and have been defined as 'attempts to explain the ultimate causes of significant social and political events and circumstances with claims of secret plots by two or more powerful actors'. ${ }^{3}$ Climate change conspiracy theories are popular, with endorsement between $20 \%^{4}$ and $40 \%^{5}$ in the USA. In other Western countries, denial is less prevalent, though still present. ${ }^{6}$

Douglas \& Sutton $^{2}$ noted climate change conspiracy theories to follow four main themes: scientists are faking climate change (a) for political reasons or (b) to secure research funding, or climate change is a hoax to (c) enable the 'green agenda' and (d) promote nuclear power. Notably, each theme implicates 'scientists' in perverse and deceptive actions. It would appear that this is required to undermine the consensus position among experts.

\section{Why do people believe climate change conspiracy theories?}

Douglas et $\mathrm{al}^{7}$ suggested that epistemic, existential and social motivations underpin conspiracy beliefs. Epistemic motivations relate to the extent to which individuals or groups hold knowledge of phenomena that affect their lives. Conspiracy beliefs are strengthened when events are significant and/or wide-reaching ${ }^{8}$ and mainstream explanations are simplistic or lacking emotional charge. ${ }^{9}$ Conspiracy beliefs can provide a sense of understanding in the face of contradiction and uncertainty, and may offer closure when mainstream narratives do not provide satisfactory explanations. ${ }^{10}$ Existential motivations relate to the experience of anxiety, threat or a perception of powerlessness in the face of danger. In such instances, conspiracy theories may provide safety. ${ }^{11,12}$ Finally, social motivations concern issues of power and hierarchy, with conspiracy theories more likely to emerge in those who have experienced oppression, victimisation or persecution. ${ }^{13}$ In such circumstances, groups can become insular and develop an 'us versus them' narrative. ${ }^{14}$ Safety is achieved through a narcissistic defence, whereby power is transferred from perceived 'elites' to the conspiracy belief holders. ${ }^{15}$ Of note, such groups are predominantly single and isolated ethnic-minority males with lower socioeconomic status and educational achievement. ${ }^{16}$

Holding one conspiracy belief increases the likelihood of believing another ${ }^{17}$ and individuals predisposed to general conspiracy thinking are more likely to deny climate change. ${ }^{18}$ An underlying tendency to prioritise counter-narrative explanations and to distrust institutions may be apparent. The notion of political socialisation is important (e.g. ${ }^{13}$ ); climate change denial is part of the conservative rhetoric and conspiracy talk that is common among world leaders such as Trump ${ }^{19}$ and Bolsonaro. ${ }^{20}$ Political polarisation of climate attitudes has been well-evidenced in the USA ${ }^{21}$ and Europe, ${ }^{6}$ among other regions. Climate change conspiracy theories might suggest allegiance to a particular conservative world view and be phenomenologically different from more emotionally charged beliefs such as the QAnon and COVID-19 conspiracy theories. 


\section{Conspiracy theories, overvalued beliefs and delusions: challenges with definitions}

Psychiatrists work with symptoms and diagnoses that are based on criteria set out by manuals such as DSM-5 and ICD-10. When criteria are met, a diagnosis can be made and a treatment plan devised. When thinking about conspiracy theories, the psychiatric terms 'overvalued ideas' and 'delusions' are challenged. Psychiatry defines 'overvalued ideas' as an erroneous response to an idea -'an acceptable, comprehensible idea pursued by the patient beyond the bounds of reason. It is usually associated with abnormal personality. ${ }^{22}$ The overvalued idea may be based on true evidence. The term was coined by Wernicke in 1906 and has further been explored by Jaspers and Fish, who made various suggestions of how to distinguish overvalued ideas from delusions. ${ }^{23}$ A delusion is defined as a 'false, unshakeable idea or belief that is out of keeping with the patient's background; it is held with extraordinary conviction and subjective certainty. ${ }^{22}$ Consequently, there can be a diagnostic dilemma as to which category climate change conspiracies - or any conspiracy theory beliefs - best align.

\section{The evidence supporting climate change conspiracy theories}

Conspiracy theory beliefs are widespread (e.g. ${ }^{24,25,26}$ ). The internet is rife with 'fake news' and 'misinformation'. Social media platforms, blogs and a whole range of other websites are dedicated to the mass propagation of 'evidence-base-less' theories that directly refute scientific findings. ${ }^{27,28}$ Bye Bye Blue Sky is one of many groups that promote and raise awareness of climate change conspiracy theories. For example, their mission statement describes 'chemtrails' and a government conspiracy to control the weather as the toxic spraying of nano particulate metals which are further amplified by ionospheric heaters to steer, direct and control our weather for military purposes... we seek to apply the wealth of our knowledge, passion and talents to end the illegal spraying of our planet' (byebyebluesky.com/). Alarmingly, the internet content and group demonstrations can be very convincing. Furthermore, some theorists have mastered the ability to navigate through such forums and use them to their advantage to disseminate their views to a large population. ${ }^{29}$

An interesting quality of conspiracy theories is that the counter-evidence is shunned by theorists who claim that the refutation of their ideas by powerful figures is further evidence of truth suppression. This introduces an 'us versus them' dynamic. ${ }^{14}$ It may also have a directly proportionate effect the stronger the evidence against the conspiracy theory, the more vehemently the counter-narrative is held. ${ }^{30}$ This is further reinforced by computer algorithms that provide a feed of confirmatory evidence and omit counter-narratives from view. ${ }^{31}$ Curiously, it is evident that the scientific community's message on climate change does not have the same footing or far-reaching sustenance as the competing conspiracy theories.

Referring back to the traditional definitions of overvalued ideas and delusions, it seems that conspiracy theories about climate change could be categorised as either or neither. A diagnostic challenge is introduced when groups or 'masses' of believers share the same conspiracy theory and it almost has the constructs of a culture. Studies ${ }^{4,5}$ have found the existence of large populations that believe conspiracy theories, supporting the idea that such beliefs extend beyond the individual. This directly causes conflict with the definition of delusions. It emphasises the need for clinicians to consider the presence of additional psychopathology and/ or functional impairment in order to make a diagnosis in an individual who is preoccupied with conspiracy beliefs. It could be postulated that this may divide psychiatrists. Some may consider that this group hold pathological beliefs, whereas others may frame the beliefs as in keeping with a 'subculture' and therefore not indicative of psychopathology.

\section{Climate change conspiracies and mental disorders}

Although there is an abundance of literature on climate change conspiracy theories in terms of their nature and spread, there appears to be very little on how such theories have had a clinical effect on mental health. In this section, the link between climate change conspiracy theories and mental disorders is discussed.

\section{Personality disorders}

Individuals with certain personality disorder diagnoses are likely to be more susceptible to preferring narratives engineered by conspiracy beliefs due to the nature of the definition in diagnostic manuals such as ICD-10. In particular, the cluster A personality disorders have the fitting profile. The description of paranoid personality disorder specifically makes reference to a 'preoccupation with unsubstantiated conspiratorial explanations of events both immediate to the patient and in the world at large'. Additional traits include recurrent suspicions without justification, general suspiciousness and a pervasive tendency to distort experience by misinterpreting neutral actions of others as hostile or malicious. Persons with a diagnosis of paranoid personality disorder may also have a rather rigid world view and an assertive sense of personal rights, which may not be proportionate to actual situations. ${ }^{32}$ It is apparent how this profile might cross over with characteristics identified in those who endorse conspiracy theories (e.g. ${ }^{7}$ ).

The ideas characteristic of paranoid personality disorder are typically persecutory and self-referential. Individuals diagnosed with this disorder are likely to be socially withdrawn and perceive that they are unduly victimised. ${ }^{33}$ Imhoff \& Lamberty ${ }^{34}$ noted similar characteristics in relation to subclinical paranoia. However, instant access to widespread networks, facilitated by the internet, allows the formation of clusters of like-minded individuals who also hold similar persecutory, self-referential ideas. There is now a mechanism by which such individuals can indulge pathologically in misinformation to bolster their false beliefs together and 'connect'. Therefore, in this scenario, selfreferential ideas become a collective experience. ${ }^{35}$ This could further add opposition to the mainstream narrative and have an impact on individual presentation.

The criteria for schizoid personality disorder include traits such as an 'invariable preference for solitary activities', 'a lack of close friends or confiding relationships', 'poor 
acknowledgement of social norms and conventions' and, importantly, 'excessive preoccupation with fantasy and introspection'. ${ }^{32}$ A combination of such traits could underpin a tendency to believe conspiracy theories.

Schizotypy is also implicated in the conspiracy theory literature. ${ }^{36}$ Schizotypy is captured in DSM-5 as a personality disorder and categorised with schizophrenia in ICD-10. March \& Springer $^{37}$ explored whether the 'odd beliefs' and 'magical thinking' seen in schizotypy predicted belief in conspiracy theories and found a significant association between the two. The authors commented that the results indicated that individuals with 'unusual patterns of thinking and cognitions' and 'interpersonal and affective' deficits were more likely to hold conspiracy beliefs. There are indications that particular personality traits are risk factors for psychosis in an attenuated form. ${ }^{38,39}$

\section{Nihilistic and apocalyptic delusions in psychotic depression}

Severe depressive disorders may have a psychotic component in which mood-congruent delusions are a feature. Nihilistic delusions, where the patient has abnormal conviction that they are dead, their organs are rotting or the world is dead around them, are not uncommon. ${ }^{40}$ There is a possibility that this belief could extend to an individual believing that they are personally responsible for climate change or in extreme cases - the destruction of the world.

Another type of delusion referred to in the literature is 'apocalyptic delusions' or 'end-of-the-world delusions'. The content of such delusions is thought to be influenced by contemporary culture and societal changes. Early content of such delusions included fears of the plague, famine and asteroids hitting the earth. ${ }^{41}$ Although these persist, the content has evolved in the present day, as would be expected, and includes despair over climate change. 'Climate apocalypse' and 'climate dystopia', are terms that encompass the idea that an apocalypse will occur as a result of climate change - severe weather changes, forest fires and a depletion of natural resources will render the earth uninhabitable and therefore bring about the inevitable impossibility of the survival of human life. ${ }^{42}$

There is a single published case study to describe this phenomenon. Wolf \& Salo ${ }^{43}$ described a 17-year-old boy diagnosed with a depressive disorder, who developed a delusion that his consumption of water would lead to the deaths of millions of people, as water supplies would be depleted. This was associated with 'visions' of an apocalypse.

Overall, there is a lack of recorded clinical cases of severe depression related to climate change or climate change conspiracy theories. However, with heightened attention on and uncertainty about climate change in modern society, there may be an increase in manifestations of this in depressive disorders through the modes suggested.

\section{Psychotic disorders}

There are controversial terms such as 'mass delusion', 'climate alarmists' and 'greenhouse sceptics', which refer to various groups of people who hold certain beliefs about climate change. ${ }^{44}$ There are conspiracy beliefs propagated by some 'climate deniers' to state that climate change is a hoax. ${ }^{45}$ Counter-conspiracy beliefs also exist, which propose that the impact of climate change is understated, data are suppressed and governments are purposefully minimising the accelerating impact on the earth to fit with their political agendas. ${ }^{2}$ In terms of psychiatric diagnosis there is no evidence to suggest that such beliefs have a delusional quality. The terms 'mass delusion' and 'climate deniers' do not have clinical connotations. Nonetheless, there is likely to be a minority with associated risk factors for psychiatric disorders within the groups who are prone to holding these beliefs with absolute conviction despite contrary scientific evidence. Such delusions may be considered part of an evolving clinical picture of a delusional disorder, or a psychotic disorder such as schizophrenia. Considering the nature of these disorders, if climate change delusions were present, they would be expected to have a bizarre quality; and it would not be unusual for extreme conspiracy theories to be the themes.

There is a small literature base - and accompanying anecdotal evidence - concerning the interplay between sociocultural events and delusional content. For example, Cannon $\&$ Kramer $^{46}$ have noted that delusional content in the USA related to syphilis in the early 20th century, Nazis during Second World War, communists during the Cold War and technology in more recent years. The internet has become increasingly relevant to delusional content (e.g. ${ }^{47,48,49}$ ). Curious case studies also exist. For example, Caseiro \& Queiros ${ }^{50}$ reported a case in which football was thematic, in the context of Portugal winning Euro 2016. Notably, psychosis is often triggered by real-world events and the nature of delusional content can reflect genuine concerns about the world, anxiety and existential threat. ${ }^{51}$

It is possible that concerns about climate change could exacerbate existing delusional beliefs, or extreme views could escalate above a delusional threshold. Consequently, such beliefs could become 'diagnosable' and meet criteria for a psychotic disorder.

\section{A psychological adjunct}

There is an association between the cognitive and affective processes that underpin conspiracy beliefs and those evidenced in delusional thinking. For example, the jumping-to-conclusions bias has been observed in psychoticlike thinking. ${ }^{52}$ This bias is associated with the overly rapid appraisal of stimuli to form a conclusion and has recently been evidenced in a sample of conspiracy theory believers. ${ }^{53}$ Poorer analytical thinking is also implicated, ${ }^{54}$ and cognitive distortions noted in depression could also be relevant. ${ }^{35}$ Similarly, historical victimisation and a schematic view of the world as dangerous are risk factors for psychosis ${ }^{55}$ and can provide a framework through which anomalous information is perceived. Individuals with schizotypal and paranoid personality disorder diagnoses are also likely to have experienced danger in their early lives ${ }^{56,57}$ and such threatening experiences are also precipitants to conspiracy beliefs. ${ }^{11,13}$ Distortions in human information processing are commonplace, adaptive and dimensional, with evidence to suggest that some individuals perceive 'true' information, whereas others omit, deny or delude as their environmental niche 
requires. ${ }^{58}$ Events that elicit threat responses are particularly relevant. Additionally, the demographic profiles of those who endorse conspiracies ${ }^{16}$ are similar to those found within psychosis cohorts. ${ }^{59}$

Many theorists and clinicians support the concept of dimensional psychosis with phenomenological continuity. ${ }^{60,61}$ Subclinical delusional thinking has been associated with conspiracy beliefs, ${ }^{62}$ as has paranoia. ${ }^{34,63}$ Conspiracy theorists may not be delusional or paranoid. However, it is plausible that they exhibit similar genetic, psychological and/or social characteristics to those who are vulnerable to psychosis. The proneness-persistence-impairment model ${ }^{61}$ and extended psychosis phenotype $^{64}$ are helpful frameworks for exploring the relationship. For many, a belief in climate change conspiracies could simply concern loyalty to conservative values. ${ }^{13}$ However, some may have an underlying predisposition to psychosis, with a tendency towards conspiracy thinking. Potential migration towards clinical thresholds could occur in response to greater perceived threat from significant events and exposure to, and preoccupation with, conspiracies. Individuals with diagnoses of paranoid or schizotypal personality disorder may fall into this position. The notion of the extended phenotype could explain why individuals who hold one conspiracy belief are more prone to believing others (e.g. ${ }^{17}$ ); this has also been called 'conspiracist ideation'. 65,66

\section{Forecast}

There is evidence to suggest that historical events have informed delusional content ${ }^{46,49}$ and there are some indications that the COVID-19 pandemic has had a recent effect. ${ }^{67}$ Delusions can be triggered by real-world events and the content can reflect genuine concerns about the world, anxiety and existential threat. ${ }^{51}$ Notably, the conditions in respect to the above phenomena were opportune for the development of conspiracy theories. That is, these events generated real threat to individuals and communities (e.g. ${ }^{7}$ ).

It can be hypothesised that the global reluctance/opposition to impactful climate policy change is actually protective with regard to the pervasive development of conspiracy belief psychopathology. That is, conspiracy theories emerge when a way of life is threatened. At present, climate policy has not had a tangible impact on freedoms, rights or lifestyle. Nonetheless, we forecast that this will likely change in the coming decades (e.g. as governments fall in line with the Paris Agreement). To our knowledge, there is only a single case study $^{43}$ to describe the interplay between climate change conspiracy beliefs and severe psychopathology. It is hypothesised that climate change has not yet become a common feature of delusional beliefs.

For those who have a predisposition to psychopathology, such changes may trigger migration towards clinical disorder. It is possible that climate change and associated conspiracy beliefs may affect mental health in the following ways: (a) dramatic societal changes (e.g. energy conservation policies, restrictions on existing freedoms) might precipitate an increase in climate change conspiracy theories, and individuals predisposed to conspiracy thinking (including those with underlying paranoid, schizoid and schizotypal traits) might migrate to delusion; (b) the increasing presence of climate change discourse in public conversations could lead to such content appearing in the content of pre-existing delusional belief systems; and (c) concerns and guilt about climate change could lead to presentations of depressive psychosis with nihilistic and/or climate-related apocalyptic delusions.

\section{Concluding remarks}

As climate change becomes more present in public consciousness, conspiracy theories are likely to become increasingly prominent and to manifest in the presentation of several mental disorders. This article has hypothesised that there may be a potential commonality between pervasive conspiracy thinking and mental disorders, particularly psychosis and certain personality disorders. However, it is proposed that clinicians approach individuals who hold conspiracy beliefs with diagnostic caution, given that conspiracy beliefs are widely held within the general population. Careful assessment is needed to identify those who are psychologically vulnerable to developing mental health complications due to exposure to conspiracy beliefs.

Further research is recommended to investigate whether a proportion of climate change conspiracy theory advocates do have underlying psychological risk factors for the development of concerning psychopathology; and also how such theories have featured in mental disorders, particularly as symptoms of psychosis or personality disorder.

\section{About the authors}

Alexander Jack is a senior forensic psychologist in the Department of Psychology, Reaside Clinic, Birmingham and Solihull Mental Health Foundation Trust, Birmingham, UK. Reena Panchal is a Year 5 Specialty Trainee (ST5) in forensic psychiatry in the Department of Psychiatry, Reaside Clinic, Birmingham and Solihull Mental Health Foundation Trust, Birmingham, UK.

\section{Acknowledgements}

A.J. thanks Dr Stephanie Wilson for her thoughts and advice on versions of this paper. R.P. thanks James Baker for his comments on several drafts of the manuscript.

\section{Author contributions}

Both authors contributed equally to the conceptualisation and writing of this paper.

\section{Funding}

This project received no specific grant from any funding agency, commercial or not-for-profit sectors

\section{Declaration of interest}

None.

\section{References}

1 Cook J, Oreskes N, Doran PT, Anderegg WR, Verheggen B, Maibach $E W$, et al. Consensus on consensus: a synthesis of consensus estimates on human-caused global warming. Environ Res Lett 2016; 11(4): 048002 
2 Douglas KM, Sutton RM. Climate change: why the conspiracy theories are dangerous. Bull At Sci 2015; 71: 98-106.

3 Douglas KM, Uscinski JE, Sutton RM, Cichocka A, Nefes T, Ang CS, et al. Understanding conspiracy theories. Pol Psychol 2019; 40: 3-5.

4 Lewandowsky S, Oberauer K, Gignac GE. NASA faked the moon landing - therefore (climate) science is a hoax: an anatomy of the motivated rejection of science. Psychol Sci 2013; 24: 622-33.

5 Cassino D. Fairleigh Dickinson University's PublicMind Poll Finds Trump Supporters More Conspiracy-Minded than Other Republicans. Fairleigh Dickinson University, 2016

6 McCright AM, Dunlap RE, Marquart-Pyatt ST. Political ideology and views about climate change in the European Union. Env Polit 2016; 25: 338-58.

7 Douglas KM, Sutton RM, Cichocka A. The psychology of conspiracy theories. Curr Dir Psychol Sci 2017; 26: 538-42.

8 Van Prooijen JW, Jostmann NB. Belief in conspiracy theories: the influence of uncertainty and perceived morality. Eur J Soc Psychol 2013; 43: 109-15.

9 Leman PJ, Cinnirella M. Beliefs in conspiracy theories and the need for cognitive closure. Front Psychol 2013; 4: 378.

10 Marchlewska M, Cichocka A, Kossowska M. Addicted to answers: need for cognitive closure and the endorsement of conspiracy beliefs. Eur J Soc Psychol 2018; 48: 109-17.

11 Abalakina-Paap M, Stephan WG, Craig T, Gregory WL. Beliefs in conspiracies. Pol Psychol 1999; 20: 637-47.

12 Newheiser AK, Farias M, Tausch N. The functional nature of conspiracy beliefs: examining the underpinnings of belief in the Da Vinci Code conspiracy. Pers Individ Dif 2011; 51: 1007-11.

13 Uscinski JE, Parent JM. American Conspiracy Theories. Oxford University Press, 2014

14 Wood MJ, Douglas KM, Sutton RM. Dead and alive: beliefs in contradictory conspiracy theories. Soc Psychol Pers Sci 2012; 3: 767-73.

15 Cichocka A, Marchlewska M, De Zavala AG. Does self-love or selfhate predict conspiracy beliefs? Narcissism, self-esteem and the endorsement of conspiracy theories. Soc Psychol Pers Sci 2016; 7: 157-66.

16 Freeman D, Bentall RP. The concomitants of conspiracy concerns. Soc Psychiatry Psychiatr Epidemiol 2017; 52: 595-604.

17 Goertzel T. Belief in conspiracy theories. Pol Psychol 1994; 15: 731-42.

18 Lewandowsky S, Oreskes N, Risbey JS, Newell BR, Smithson M Seepage: climate change denial and its effect on the scientific community. Glob Environ Change 2015; 33: 1-3.

19 De Pryck K, Gemenne F. The denier-in-chief: climate change, science and the election of Donald J. Trump. Law Crit 2017; 28: 119-26.

20 Escobar H. Bolsonaro's first moves have Brazilian scientists worried. Science 2019; 363: 330.

21 Dunlap RE, McCright AM. Organized climate change denial. In The Oxford Handbook of Climate Change and Society (eds JS Dryzek, RB Norgaard, D Schlosberg): 144-60. Oxford University Press, 2011.

22 Oyebode F. Sims' Symptoms in the Mind: An Introduction to Descriptive Psychopathology. Elsevier Health Sciences, 2008.

23 Kiran C, Chaudhury S. Understanding delusions. Ind Psychiatry J 2009; 18: 3-18.

24 Drochon $\mathrm{H}$. Who believes in conspiracy theories in Great Britain and Europe. In Conspiracy Theories and the People Who Believe Them (ed JE Uscinski): 337-46. Oxford University Press, 2018.

25 Enders AM, Smallpage SM. Polls, plots and party politics: Conspiracy theories in contemporary America. In Conspiracy Theories and the People Who Believe Them (ed JE Uscinski): 298-318. Oxford University Press, 2018.

26 Freeman D, Waite F, Rosebrock L, Petit A, Causier C, East A, et al. Coronavirus conspiracy beliefs, mistrust and compliance with government guidelines in England. Psychol Med [Epub ahead of print] 21 May 2020. Available from: https://doi.org/10.1017/S0033291720001890.

27 Shao C, Ciampaglia GL, Varol O, Yang KC, Flammini A, Menczer F. The spread of low-credibility content by social bots. Nat Commun 2018; 9(1): 4787.
28 Treen KM, Williams HT, O'Neill SJ. Online misinformation about climate change. Wiley Interdiscipl Rev Clim Change 2020; 11(5): e665.

29 Van den Bulck $H$, Hyzen A. Of lizards and ideological entrepreneurs: Alex Jones and Infowars in the relationship between populist nationalism and the post-global media ecology. Int Commun Gaz 2020; 82: 42-59.

30 Uscinski JE, Douglas K, Lewandowsky S. Climate change conspiracy theories. In Oxford Research Encyclopedia of Climate Science (eds $\mathrm{H}$ von Storch, I Auer, H Brooks, M Claussen, H Dolman, R Grundmann, et al.): 26 Sep. Oxford University Press, 2017.

31 Faddoul M, Chaslot G, Farid H. A longitudinal analysis of YouTube's promotion of conspiracy videos. arXiv:2003.03318. Cornell University, 2020.

32 World Health Organization. The ICD-10 Classification of Mental and Behavioural Disorders: Diagnostic Criteria for Research. World Health Organization, 1993

33 Carroll A. Are you looking at me? Understanding and managing paranoid personality disorder. In Clinical Topics in Personality Disorder (eds J Sarkar, G Adshead): 53-69. RCPsych Publications, 2012.

34 Imhoff R, Lamberty P. How paranoid are conspiracy believers? Toward a more fine-grained understanding of the connect and disconnect between paranoia and belief in conspiracy theories. Eur J Soc Psychol 2018; 48: 909-26.

35 Pierre JM. Integrating non-psychiatric models of delusion-like beliefs into forensic psychiatric assessment. J Am Acad Psychiatry Law 2019; 47: 171-9.

36 Darwin $\mathrm{H}$, Neave N, Holmes J. Belief in conspiracy theories. The role of paranormal belief, paranoid ideation and schizotypy. Pers Individ Dif 2011; 50(8): 1289-93.

37 March E, Springer J. Belief in conspiracy theories: the predictive role of schizotypy, Machiavellianism and primary psychopathy. PLoS One 2019; 14(12): e0225964.

38 Nelson MT, Seal ML, Pantelis C, Phillips LJ. Evidence of a dimensional relationship between schizotypy and schizophrenia: a systematic review. Neurosci Biobehav Rev 2013; 37(3): 317-27.

39 Ohi K, Hashimoto R, Yasuda Y, Fukumoto M, Yamamori H, Iwase M, et al. Personality traits and schizophrenia: evidence from a case-control study and meta-analysis. Psychiatry Res 2012; 198: 7-11.

40 Radovic $F$. The sense of death and non-existence in nihilistic delusions. Phenomenol Cogn Sci 2017; 16: 679-99.

41 Rudalevičienè $P$, Narbekovas A, Bunevičius R, Stompe T. Influence of culture on the world end (apocalyptic) delusions. World Cult Psychiatry Res Rev 2008; 3: 96-105.

42 Hjerpe $M$, Linnér BO. Utopian and dystopian thought in climate change science and policy. Futures 2009; 41: 234-45.

43 Wolf J, Salo R. Water, water, everywhere, nor any drop to drink: climate change delusion. Aust N Z J Psychiatry 2008; 42: 350.

44 Jaspal R, Nerlich B, Van Vuuren K. Embracing and resisting climate identities in the Australian press: sceptics, scientists and politics. Public Underst Sci 2016; 25: 807-24.

45 Washington H, Cook J. Climate Change Denial: Heads in the Sand. Earthscan, 2011

46 Cannon BJ, Kramer LM. Delusion content across the 20th century in an American psychiatric hospital. Int J Soc Psychiatry 2012; 58: 323-7.

47 Bell V, Grech E, Maiden C, Halligan PW, Ellis HD. 'Internet delusions': a case series and theoretical integration. Psychopathology 2005; 38: 144-50.

48 Nitzan U, Shoshan E, Lev-Ran S, Fennig S. Internet-related psychosis a sign of the times? Isr J Psychiatry Relat Sci 2011; 48: 207-11.

49 Škodlar B, Dernovšek MZ, Kocmur M. Psychopathology of schizophrenia in Ljubljana (Slovenia) from 1881 to 2000: changes in the content of delusions in schizophrenia patients related to various sociopolitical technical and scientific changes. Int J Soc Psychiatry 2008; 54: 101-11.

50 Caseiro J, Queiros O. The influence of socio-cultural features in the contents of delusions, football delusion-Two Clinical cases. Birth Growth Med J 2018; 27: 188-90 
51 Longden E, Madill A, Waterman MG. Dissociation, trauma and the role of lived experience: toward a new conceptualization of voice hearing. Psychol Bull 2012; 138: 28-76.

52 Garety PA, Freeman D. The past and future of delusions research: from the inexplicable to the treatable. Br J Psychiatry 2013; 203: 327-33.

53 Pytlik N, Soll D, Mehl S. Thinking preferences and conspiracy belief: intuitive thinking and the jumping to conclusions-bias as a basis for the belief in conspiracy theories. Front Psychiatry 2020; 11: 987.

54 Swami V, Voracek M, Stieger S, Tran US, Furnham A. Analytic thinking reduces belief in conspiracy theories. Cognition 2014; 133: 572-85.

55 Moulding R, Nix-Carnell S, Schnabel A, Nedeljkovic M, Burnside EE, Lentini $A F$, et al. Better the devil you know than a world you don't? Intolerance of uncertainty and worldview explanations for belief in conspiracy theories. Pers Individ Dif 2016; 98: 345-54.

56 Perry C, Lee R. Childhood trauma and personality disorder. In Childhood Trauma in Mental Disorders: A Comprehensive Approach (eds G Spalletta, D Janiri, F Piras, G Sani): 231-55. Springer, 2020

57 Velikonja T, Velthorst E, McClure MM, Rutter S, Calabrese WR, Rosell $D$, et al. Severe childhood trauma and clinical and neurocognitive features in schizotypal personality disorder. Acta Psychiatr Scand 2019; 140: $50-64$

58 Crittenden PM, Landini A. Assessing Adult Attachment: A Dynamic-Maturational Approach to Discourse Analysis. WW Norton, 2011

59 Cornblatt BA, Carrión RE, Addington J, Seidman L, Walker EF, Cannon TD, et al. Risk factors for psychosis: impaired social and role functioning. Schizophr Bull 2012; 38: 1247-57.
60 DeRosse $\mathrm{P}$, Karlsgodt KH. Examining the psychosis continuum. Curr Behav Neurosci Rep 2015; 2: 80-9.

61 van Os J, Linscott RJ, Myin-Germeys I, Delespaul P, Krabbendam LJ. A systematic review and meta-analysis of the psychosis continuum: evidence for a psychosis proneness-persistence-impairment model of psychotic disorder. Psychol Med 2009; 39: 179-95.

62 Dagnall N, Drinkwater K, Parker A, Denovan A, Parton M. Conspiracy theory and cognitive style: a worldview. Front Psychol 2015; 6: 206.

63 Grzesiak-Feldman M, Ejsmont A. Paranoia and conspiracy thinking of Jews, Arabs, Germans and Russians in a Polish sample. Psychol Rep 2008; 102: 884-6.

64 van Os J, Reininghaus U. Psychosis as a transdiagnostic and extended phenotype in the general population. World Psychiatry 2016; 15: 118-24

65 Swami V, Coles R, Stieger S, Pietschnig J, Furnham A, Rehim S, et al. Conspiracist ideation in Britain and Austria: evidence of a monological belief system and associations between individual psychological differences and real-world and fictitious conspiracy theories. $\mathrm{Br} J$ Psychol 2011; 102: 443-63.

66 Brotherton R, Eser S. Bored to fears: boredom proneness, paranoia and conspiracy theories. Pers Individ Dif 2015; 80: 1-5.

67 Larsen EM, Donaldson K, Mohanty A. Conspiratorial thinking during COVID-19: The roles of paranoia, delusion-proneness and intolerance to uncertainty. PsyArXiv [preprint] 17 Jun 2020. Available from: https://doi.org/10.31234/osf.io/mb65f.

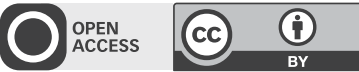

\title{
SPECIAL ARTICLE
}

\section{What mental health professionals and organisations should do to address climate change}

\author{
Adam Monsell, ${ }^{1}$ (i) Jacob Krzanowski, ${ }^{2}$ (1) Lisa Page, ${ }^{3}$ Sharon Cuthbert, ${ }^{4}$ (1) Guy Harvey ${ }^{5}$
}

BJPsych Bulletin (2021) 45, 215-221, doi:10.1192/bjb.2021.17

${ }^{1}$ Camden and Islington Mental Health and Social Care Trust, UK; ${ }^{2}$ South London and Maudsley Mental Health NHS Trust, UK: ${ }^{3}$ Sussex Partnership NHS Foundation Trust, UK; ${ }^{4}$ Sussex Partnership NHS Foundation Trust, UK ${ }^{5}$ Cumbria Northumberland Tyne and Wear NHS Foundation Trust, UK Correspondence to Adam Monsell (Adam.monsell@nhs.net)

First received 11 Nov 2020, accepted 19 Jan 2021

(C) The Authors 2021. Published by Cambridge University Press on behalf of The Royal College of Psychiatrists. This is an Open Access article, distributed under the terms of the Creative

Commons Attribution licence (http:// creativecommons.org/licenses/by/4. $0 /$ ), which permits unrestricted re-use distribution, and reproduction in any medium, provided the original work is properly cited.
Aims and method The climate change emergency is also a mental healthcare emergency. We seek to provide a framework for what mental health professionals and organisations should do to make their practice more sustainable.

Results There are ethical, legal and organisational imperatives to make mental healthcare more sustainable. Mental healthcare must be refocused with an emphasis on prevention, building social capital and community resilience. Patients must be empowered to manage their own mental health. Efficiencies should be found within the system. Low-carbon ways to deliver care must be found, measured and improved upon. Greater adaptability needs to be built into the system to mitigate the impact of climate change. Sustainability should be integrated into training programmes, and good examples of practice shared and celebrated.

Clinical implications Mental health organisations and individuals must act now to prevent and adapt for the climate and ecological emergency. Sustainable practice is also good practice.

Keywords Sustainability; climate change; mental health; psychiatry; carbon footprint. 